Journal of Social Sciences (COES\&RJ-JSS)

ISSN (E): 2305-9249 ISSN (P): 2305-9494

Publisher: Centre of Excellence for Scientific \& Research Journalism, COES\&RJ LLC

Online Publication Date: $1^{\text {st }}$ January 2017

Online Issue: Volume 6, Number 1, January 2017

https://doi.org/10.25255/jss.2017.6.1.14.28

\title{
Technological and Structural Inputs for the Purposes of Strategic Change in Business Organizations: An Empirical Study at Talal Abu- Ghazaleh Organization
}

\author{
Dr. Dmaithan Abdelkarim Almajali \\ Assistant Professor of Management Information Systems, Management Information \\ Systems Department, Faculty of Economics and Administrative Sciences, \\ Zarqa University, Zarqa, Jordan \\ Dr. Ala'aldin Alrowwad \\ Department of Business Administration, Faculty of Management and Finance, \\ University of Jordan, Aqaba Branch \\ Nurah Musa Allozi \\ Department of Accounting, School of Business, \\ The University of Jordan
}

\begin{abstract}
:
This study aimed to identify the obstacles to achieving ongoing strategic changes in business organizations within the framework of transition to electronic systems and the analysis of these obstacles in order to reach more effective in dealing with the recommendations. The study population consisted of Talal Abu-Ghazaleh International Inc. A staff of 300 employees was selected from the staff Talal Abu Ghazaleh organization. It was the use of statistical package (SPSS) to find averages, standard deviations, and the relative importance of the answers to the study sample. The study found that levels of variation (difference) in the circuit between the administrative case activities before and after the web was the medium run, the administrative confusion levels that you get as a result of the electronic network downtime in the company were low, and the usual temporal dimensions of the cases of administrative confusion in cases of electronic network was low crashes, the employment levels of the following methods in order to avoid cases of electronic network stopped at the company was a medium, and the levels of employment of roads therapeutically for cases when the electronic network stopped at the company was usually moderate.
\end{abstract}

Keywords:

Strategic Change, Business Organizations, Talal Abu-Ghazaleh, Jordan.

Citation:

Almajali, Dr. Dmaithan Abdelkarim; Alrowwad, Dr. Ala'aldin; Allozi, Nurah Musa (2017); Technological and Structural Inputs for the Purposes of Strategic Change in Business Organizations: An Empirical Study at Talal Abu-Ghazaleh Organization; Journal of Social Sciences (COES\&RJ-JSS), Vol.6, No.1, pp: 14-28; https://doi.org/10.25255/jss.2017.6.1.14.28. 


\title{
المدخلات التكنولوجية و الهيكلية لأغراض التغيير الاستراتيجي في منظمات الأعمال: دراسة

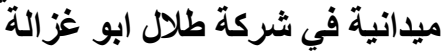

\author{
د. دميثان عبدالكريم المجالي، قسم نظم المعلومات الادارية، كلية الاقتصاد و العلوم الادارية، جامعة الزرقاء،

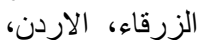

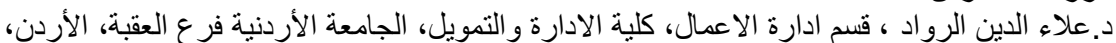

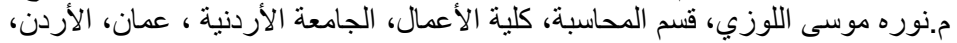

هدفت هذه الدراسة للتعرف على معوقات تحقيق التغيرات الإستراتيجية الجارية في منظمات الأعمال في إطار

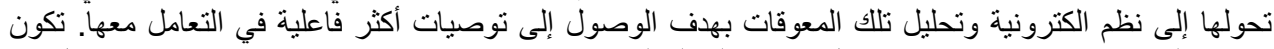

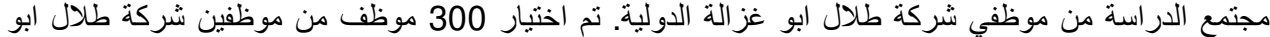

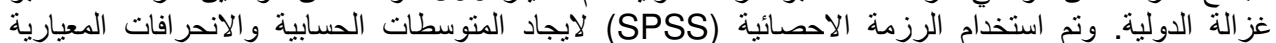

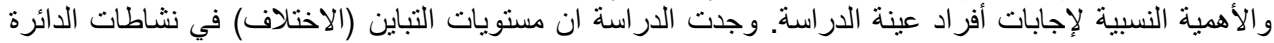

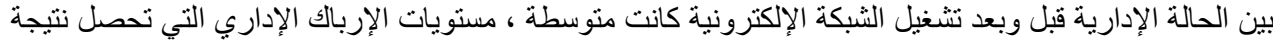

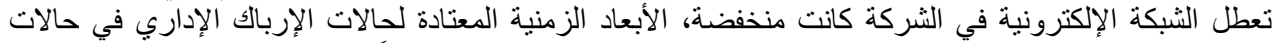

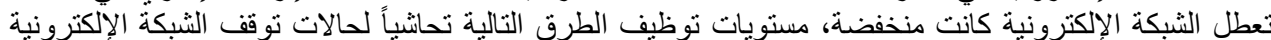

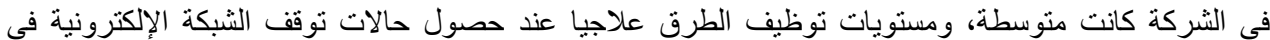
الشركة عادة كانت متوسطة.

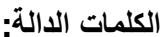
التغيير الاستر اتيجي ، منظمات الأعمال ، شركة طلال ابو غزالة ، الاردن.

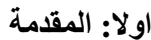
يعد التغيير أمر حتمي وضروروي في أي منثأة، إذ أنه عملية مستمرة ومتجددة وهو بذلك يتناسق مع طبيعة الأشياء

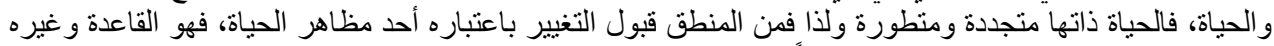

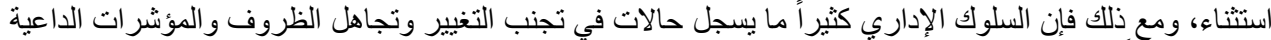

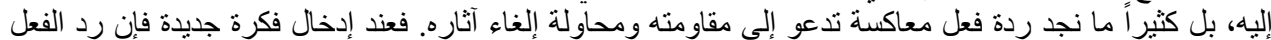

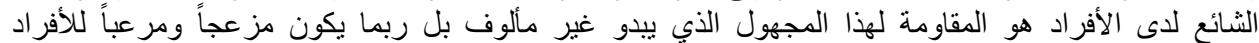
(Masa'deh \& Others, 2015)

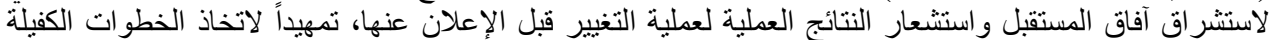

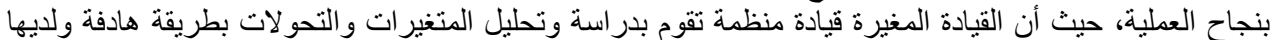

القدرة على تحريك الموارد في مجالات ذات إنتاجية متدنية إلى إنتاجية أكبر (Alkalha \& Others, 2012).

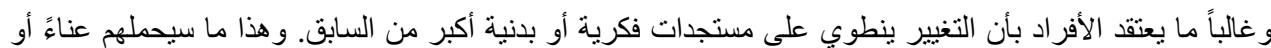

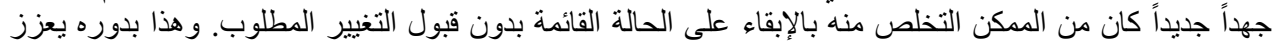

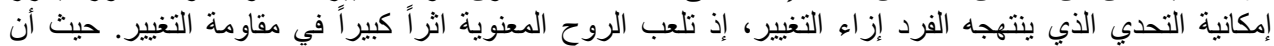

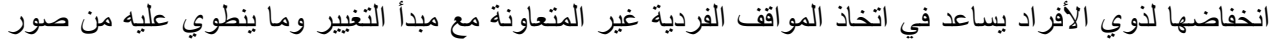

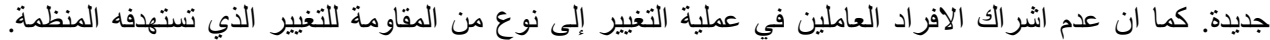

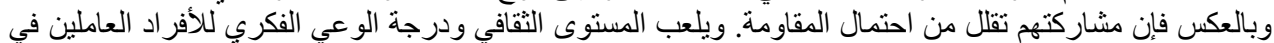

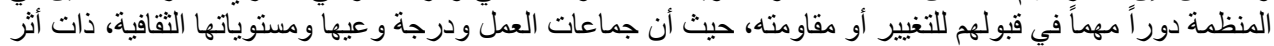

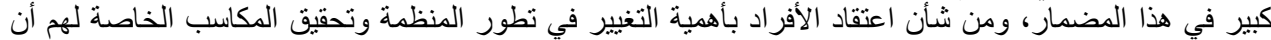
يقلل من مقاومتهم به (Masa'deh \& Others, 2016).

هاف البحث

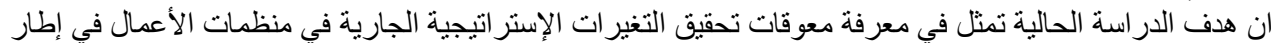

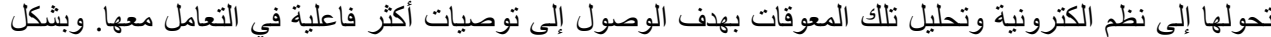
اكثر تتمحور مشكلة الدر اسة من خلال الاجابة عن التساؤلات الفر الئة الفية التالية: 


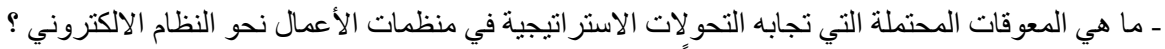

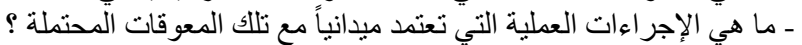

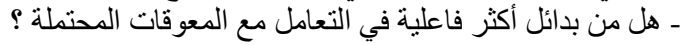

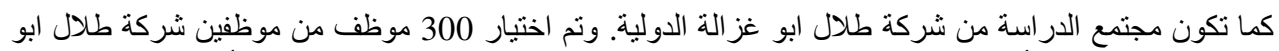

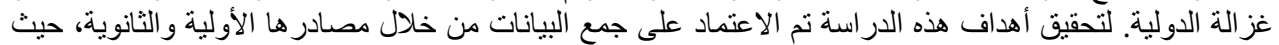

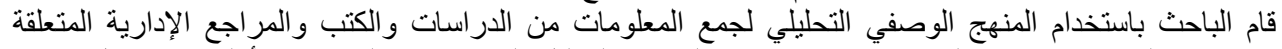

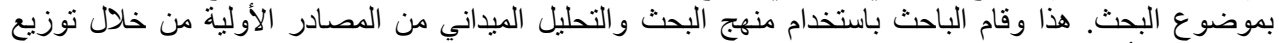
استبانة تخدم أهداف الدر اسة.

واعتمدت الدراسة على نوعين من مصادر البيانات وهما مصادر البيانات الثانوية من خلال المراجع والداراسات

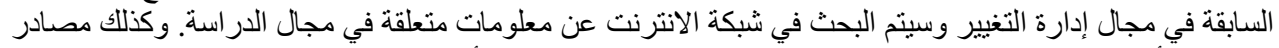

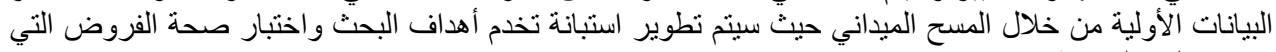
ستقوم عليها الدر اسة.

ثانيا: الإطار النظري

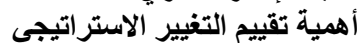

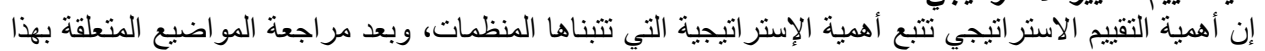

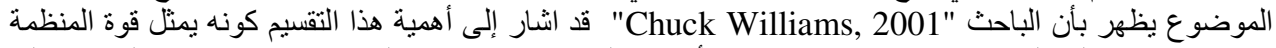

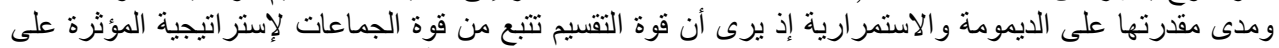

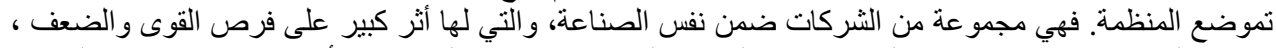

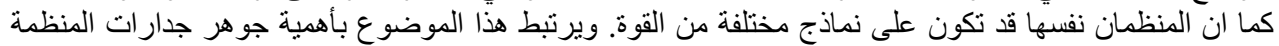

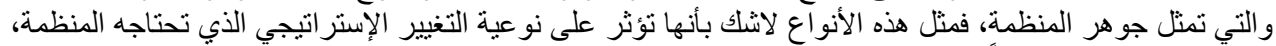
وقد يكون هذا التغيير ناتجاً عن التأثير ات البيئية المحيطة. لأنئ.

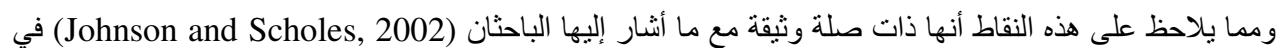

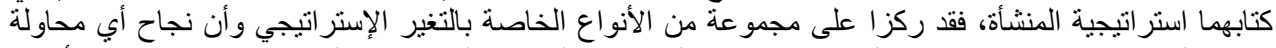

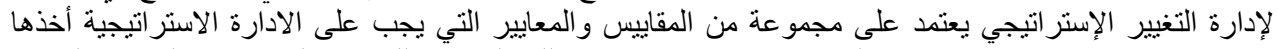

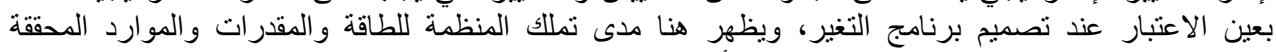

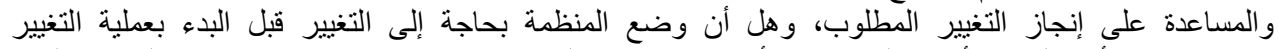

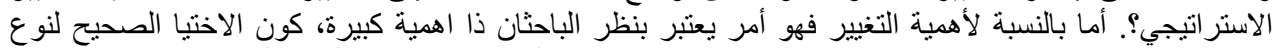

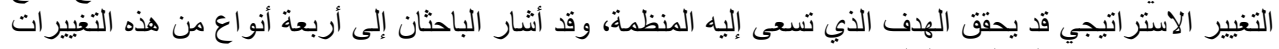
الإستر اتيجية، وهي على النئين النحو التالي:

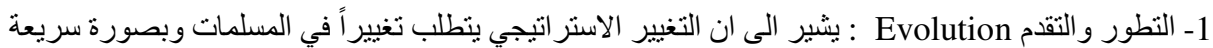

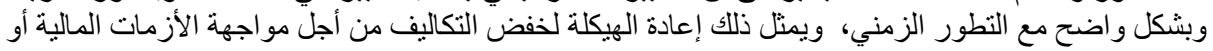

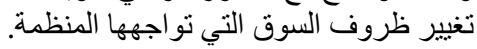

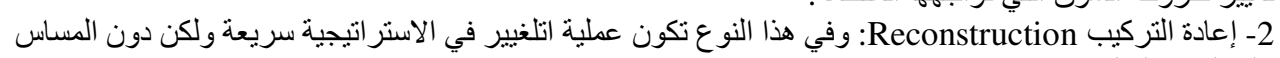
بالمسلمات المالية.

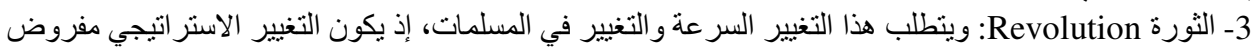

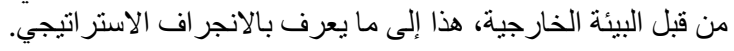

أساليب إدارة التغيير الاستراتيجي .

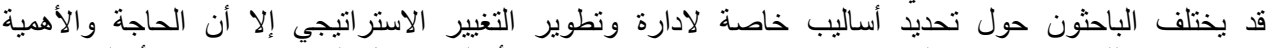

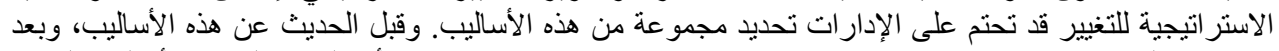

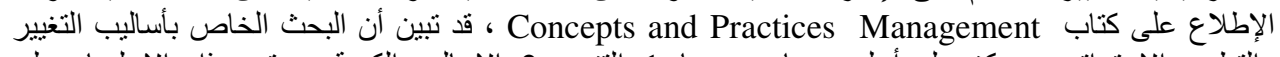

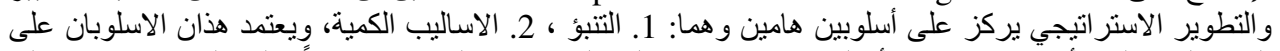

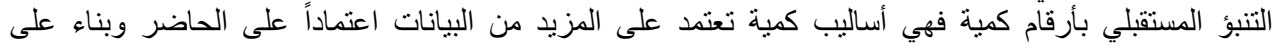




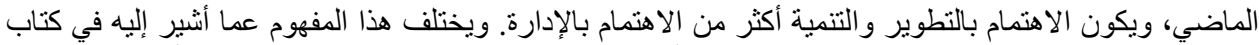
Exploring Corporate Strategy

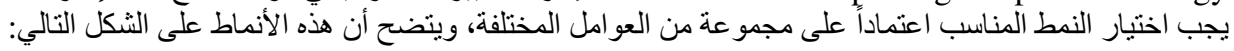

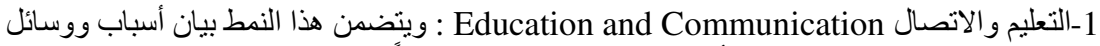

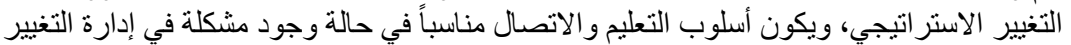

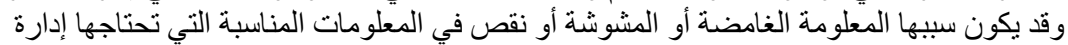

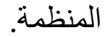

2-التوجيه و الإشر اف Direction : ويتضمن هذا الأسلوب استعمال السلطة الإدارية الثخصية في تأسيس

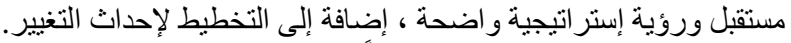

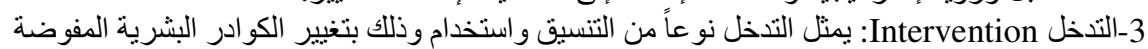

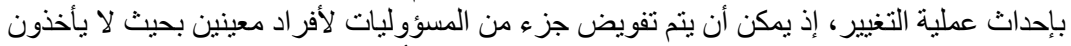

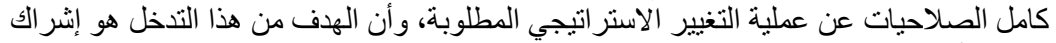

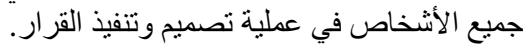

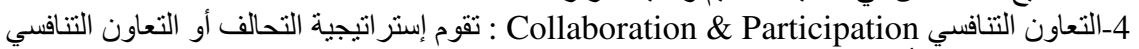

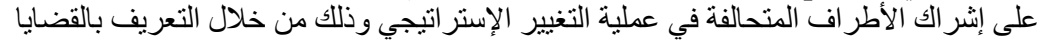

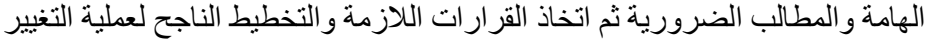
الاستر اتيجي، وقد يعطي هذا الأسلوب أفضل الندان النتائج المتحققة.

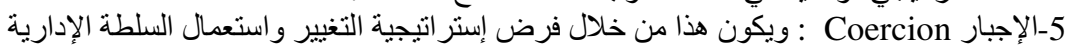

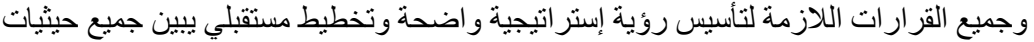
ومكونات عملية التغيير.

تحليل إستراتيجية التغيير والتطوير تحليل القوى المشاركة والموئثير والئروير

يتشابه هذا الموضوع بين العديد من الدراسات، فقد أثار المؤلف Chuck Williams (2001) في كتابه الإدارة

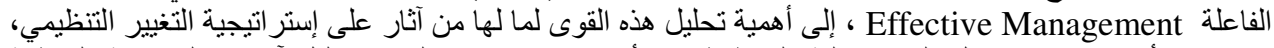

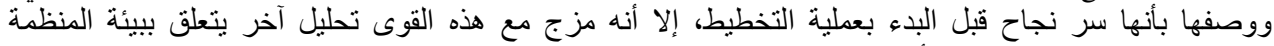

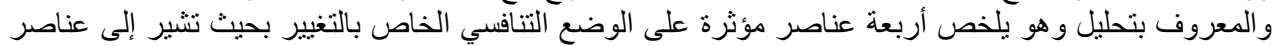

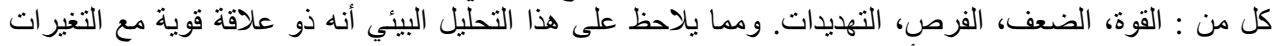

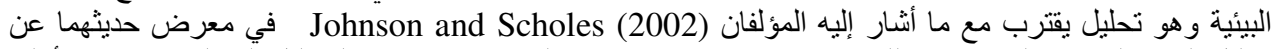

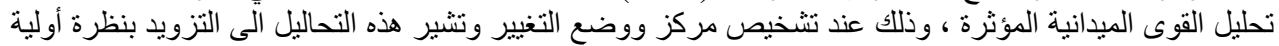

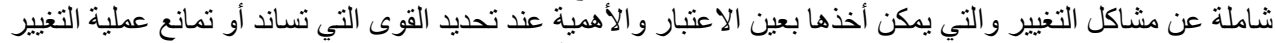
الاستر اتيجي، وقد اورد هذا التحليل مجمو عة من النقاط التي يمكن أن تساعد على تحليل النسيج التقافي في ذلك، مثل:

$$
\begin{aligned}
& \text { أهمية الجو انب الثقافية الحالية التي يمكن ان تساعد على عملية التغيير الاستر اتيجي في الاتجاه المطلوب، وكيف يمكن }
\end{aligned}
$$

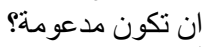

$$
\begin{aligned}
& \text { أهمية الجو انب الثقافية الحالية التي يمكن ان تكون عائقاً في التغيير، وكيف يمكن التغلب و السيطرة عليها؟ }
\end{aligned}
$$

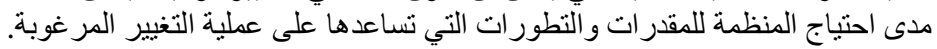

التحديات المواجهة لإدارة التغيير الاستراتيجي:

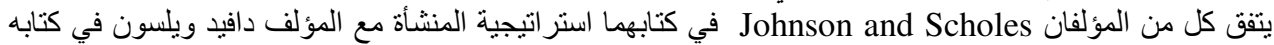

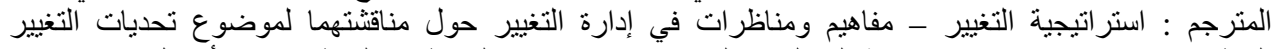

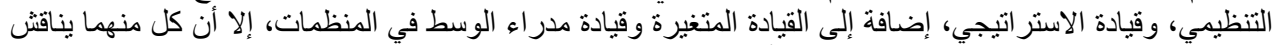

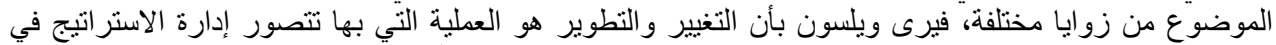

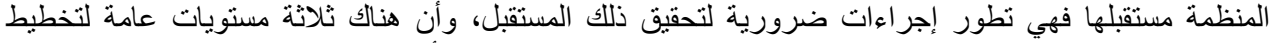

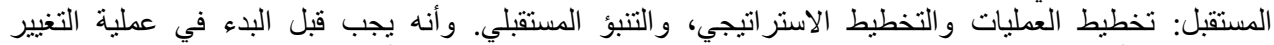

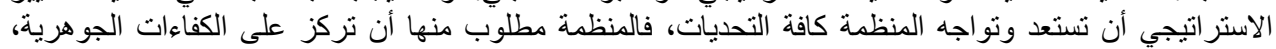

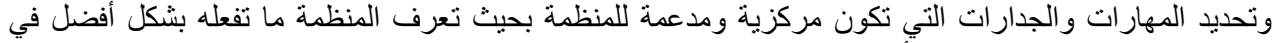

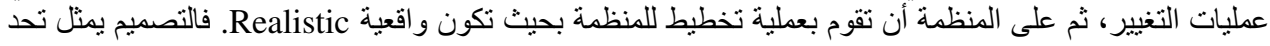




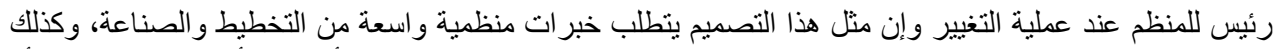

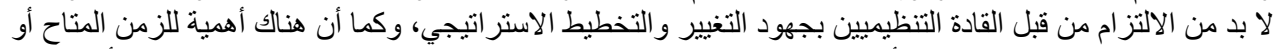

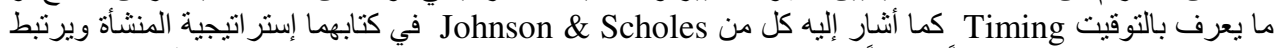

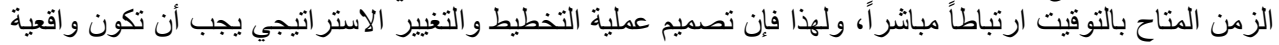
ومختارة في الوقت المناسب (عامر سعيد، 2001) .

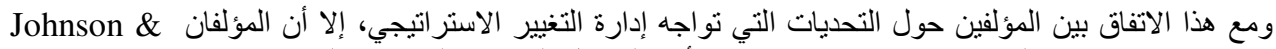
Scholes

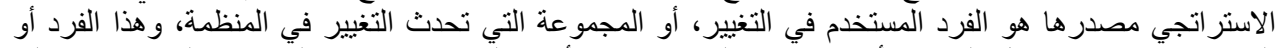

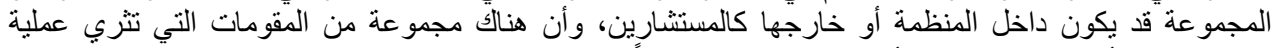

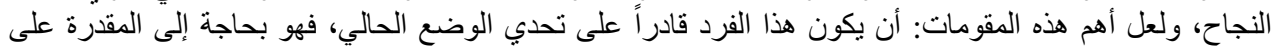

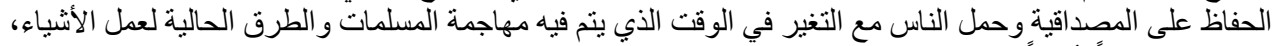

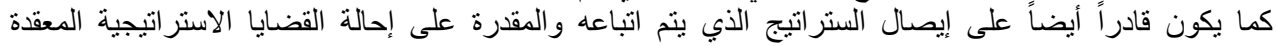

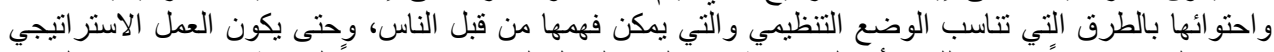

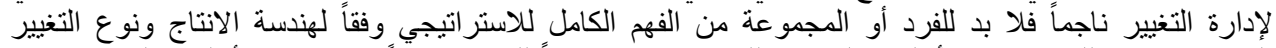

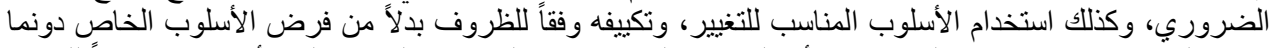

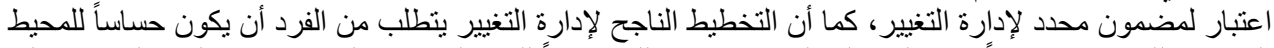

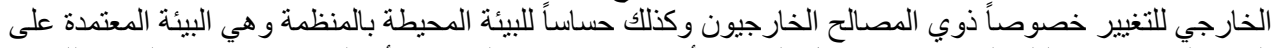

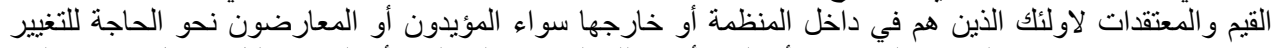

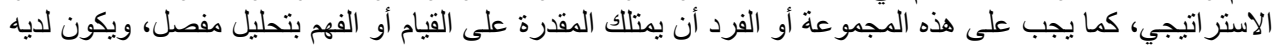

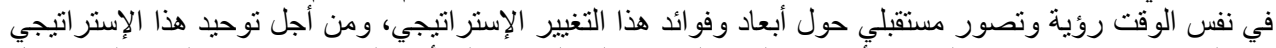

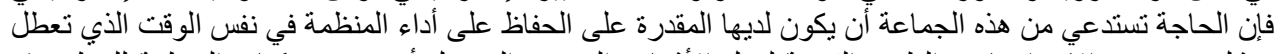

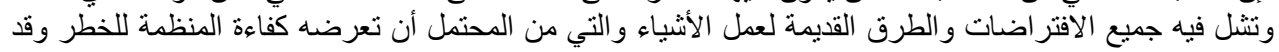

تؤدي غلى زو اللها.

مدثل مدراء الإدارة الوسط المستوى والخارجيون:

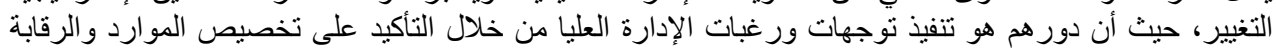

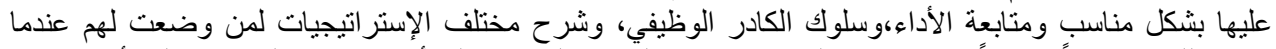

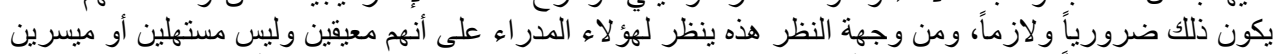

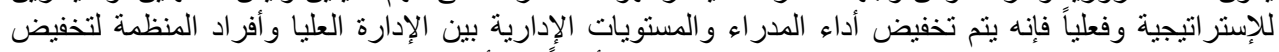

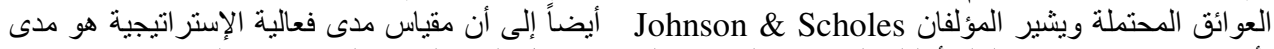

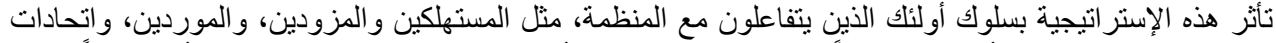

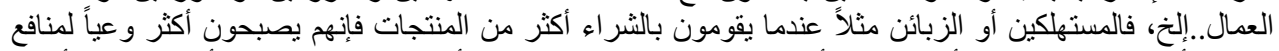

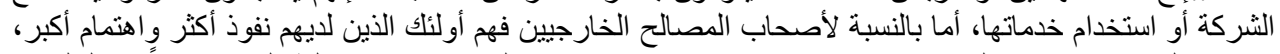

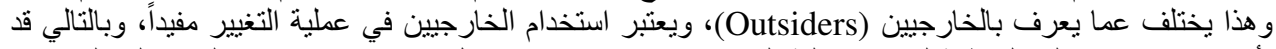

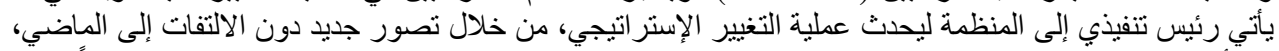

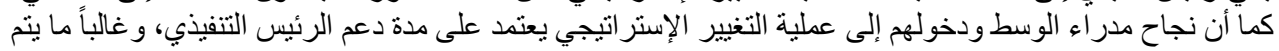

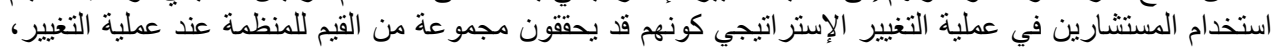
وقد يعود ذلك لسببين:

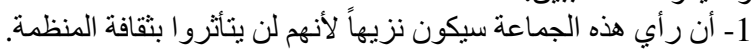

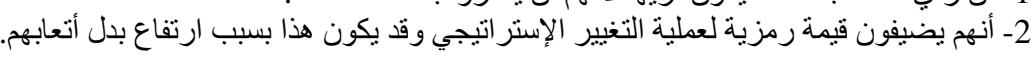

التغيير الإستراتيجي كمدخل لتعزيز القدرة التنافسية:

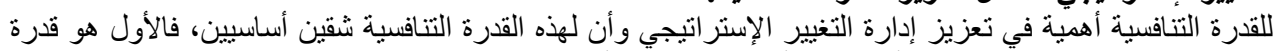

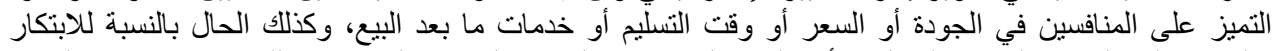

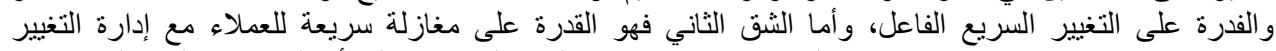

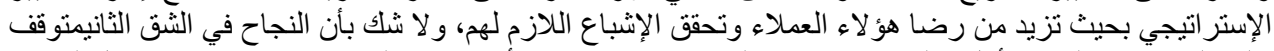

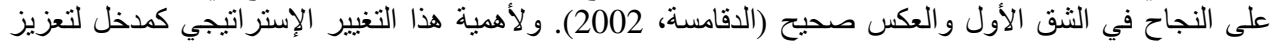


Technological and Structural Inputs....

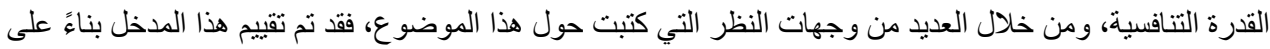

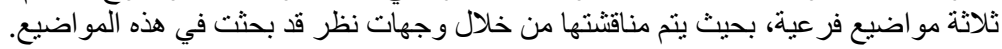

التغيير المخطط وغير المخطط:

يشتمل التغيير المخطط و التغيير غير المخطط وفقاً لهذه المناقثة على ثلاثة قضايا رئيسية: قضايا التغيير المخطط،

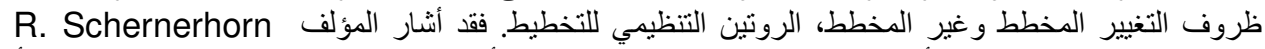

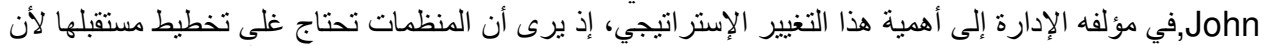

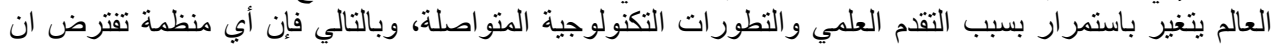

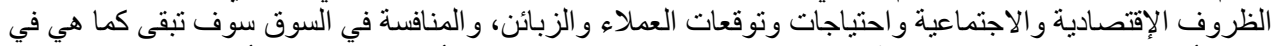

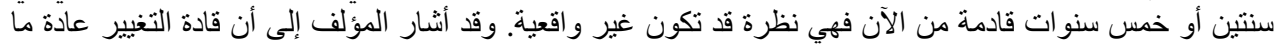

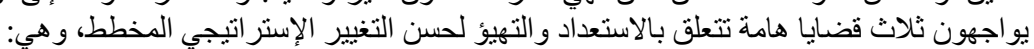

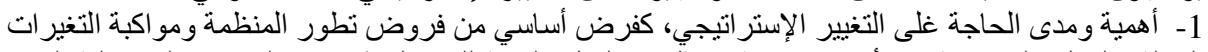

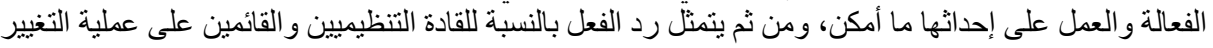

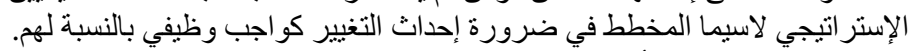

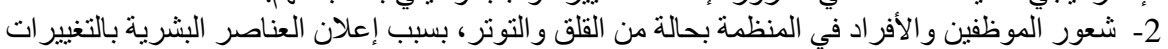

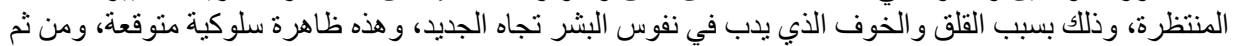

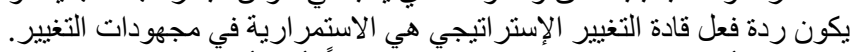

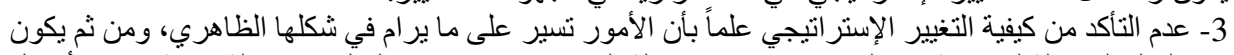

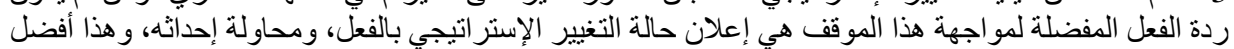
على أبي حال من التردد بسبب عدم التأكد.

أما المؤلفان Johnson \& Scholes ، فقد ناقثنا الموضو ع الخاص بالتغيير الإستراتيجي ( المخطط وغير المخطط)

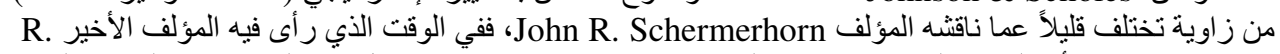
Schermerhorn

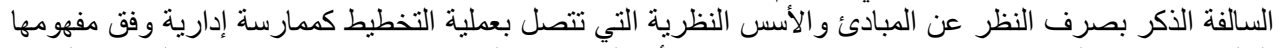

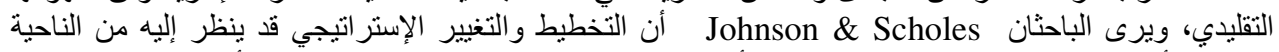

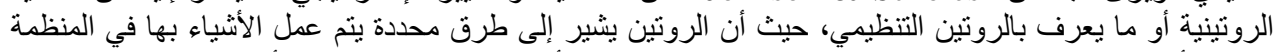

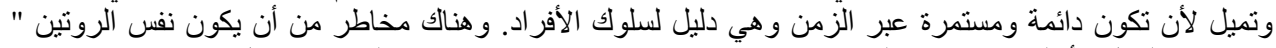

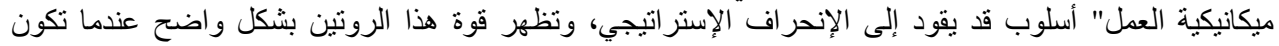
الحاجة لوضع استر اتيجية جديدة.

المعالجة مع مقاومة التغيير الإستراتيجي:

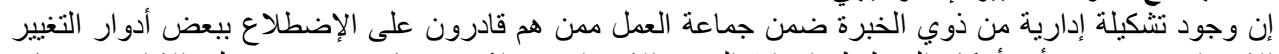

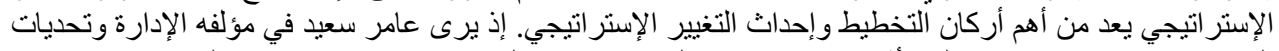

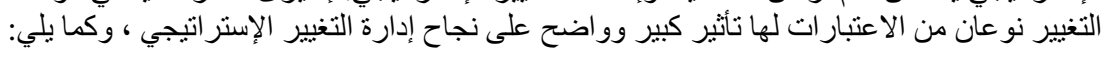

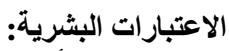

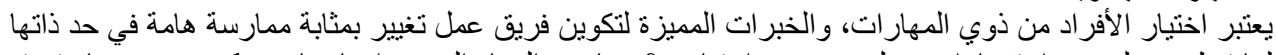

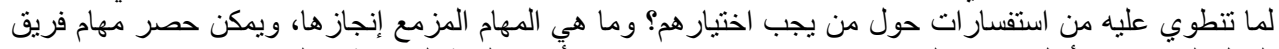

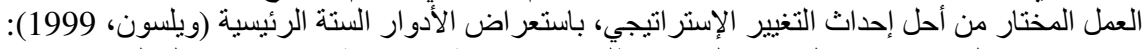

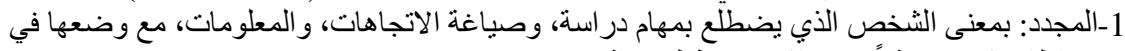

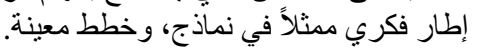

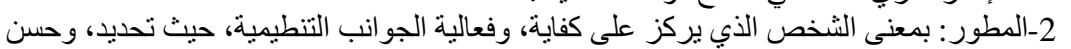

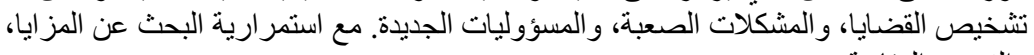

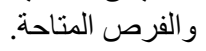

3-الموفق: بمعنى الثخص الذي يبذل الجهر من أجل كسب تقبل العناصر البشرية، و الأفكار، ومجهودات

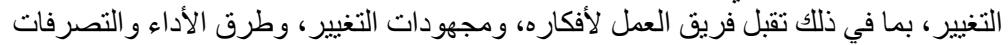

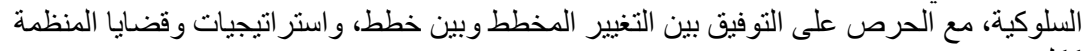

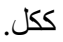




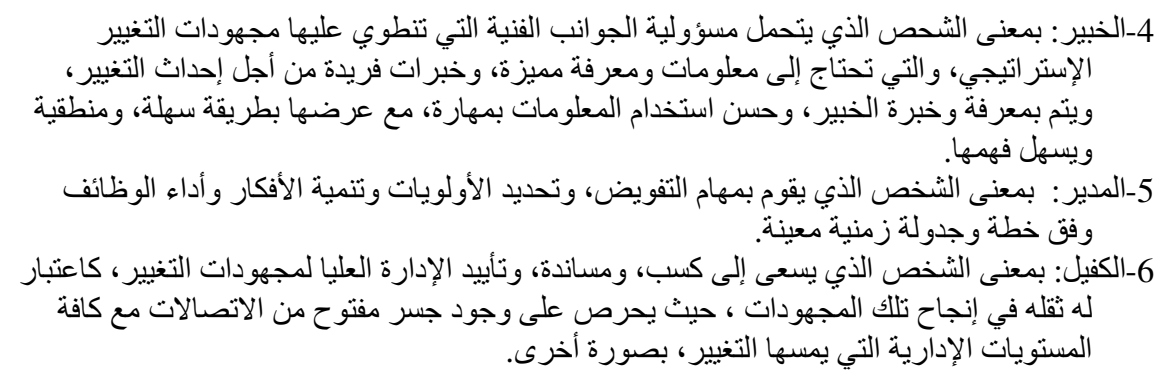

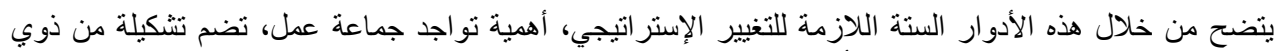

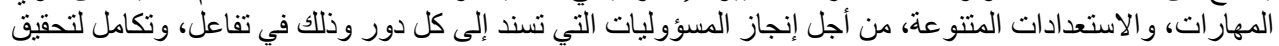

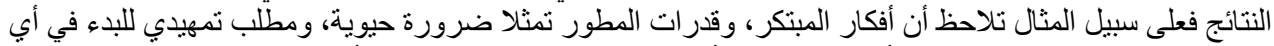

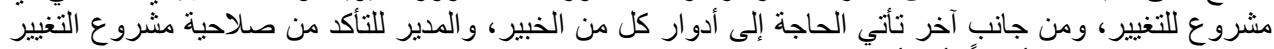

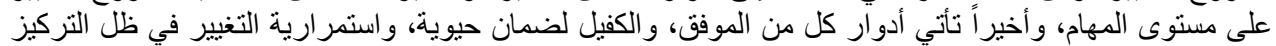

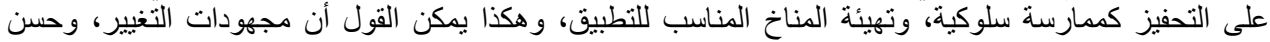

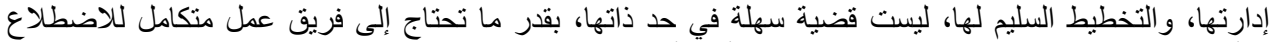

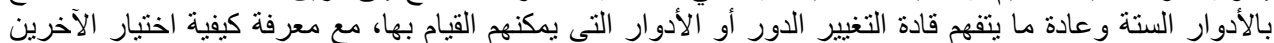

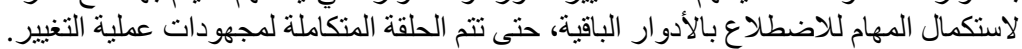

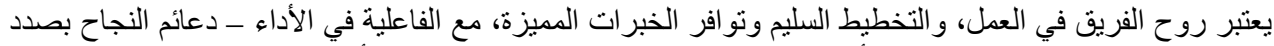

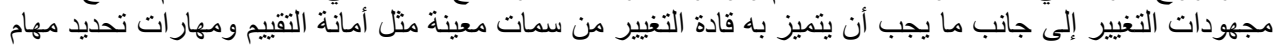
الآخرين، و غير ذلك.

\section{الاعتبارات التطبيقية:}

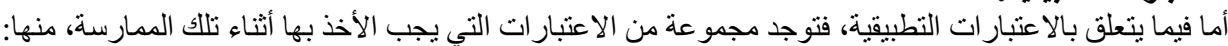

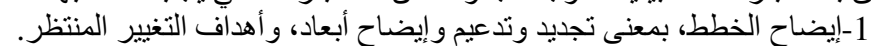

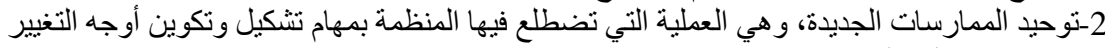
بمو اقعها المختلفة.

3-تنوفير التعليم اللازم، وتنطوي تلك الممارسة على إعداد البرامج التعليمية التي يستفيد منها المنفذين

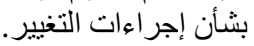

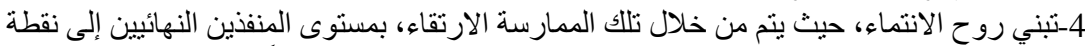

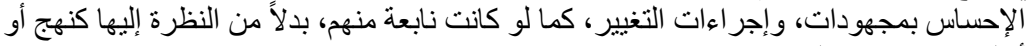

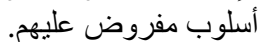

5-ممارسة رد الفعل الطبيعي لإحداث التغيير ، من خلال تشجيع المعلومة المرتدة، وهي العملية التي يتم من خلالها استخدام تفاصيل الأهداف للحكم على مدى فاعلية تطبيق الخطط الفئ المقترحة.

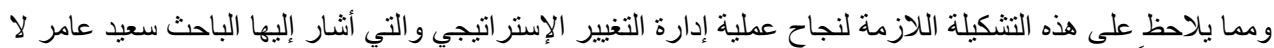

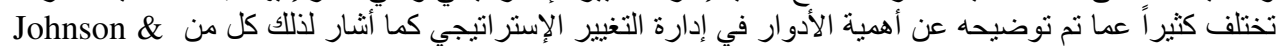

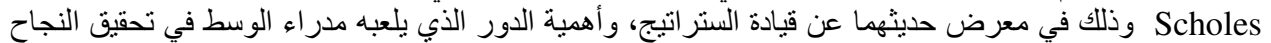

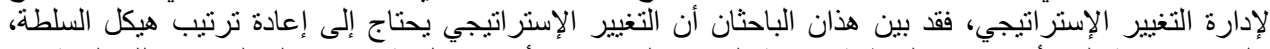

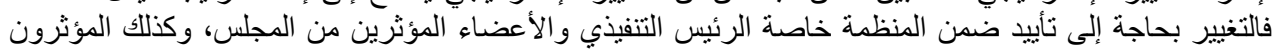

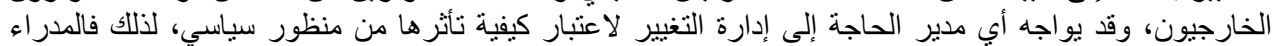

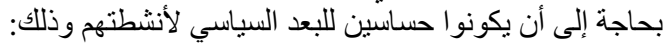

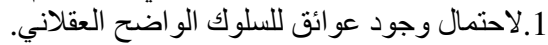

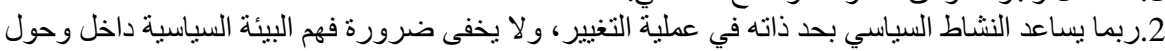

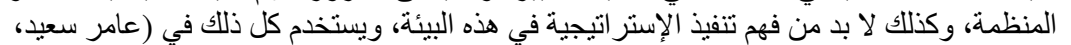

:(2001

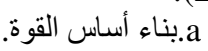


Technological and Structural Inputs....

$$
\begin{aligned}
& \text { b.دعم التتجيع أو التظلب على الدقاومة. } \\
& \text { تحقيق التزام بالستر اتيج أو أي جزء من النشاط. }
\end{aligned}
$$

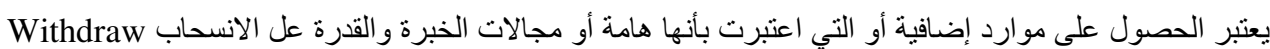

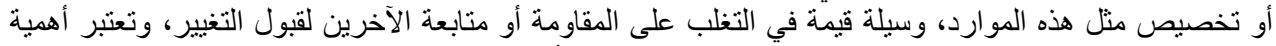

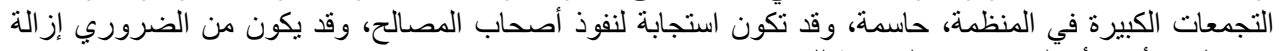
(تحريك) الأفر اد أو المجمو عات الدقاومة للتغيير.

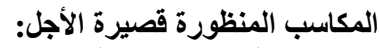

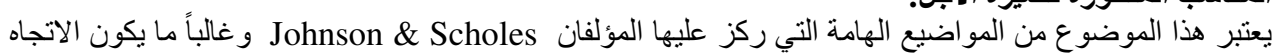

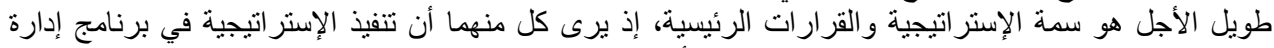

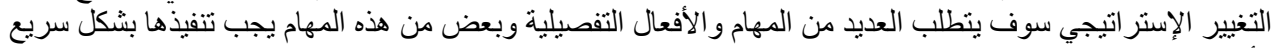

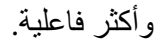

اختيار إستراتيجية التغيير: يشير هذا الموضوع إلى التوقيت المناسب وأهمية اختيار إستراتيجية التغيير المناسبة، وفق تسلسل الأحداث حيث

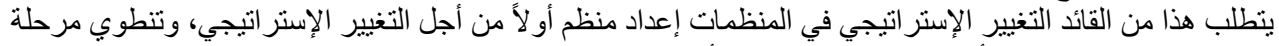

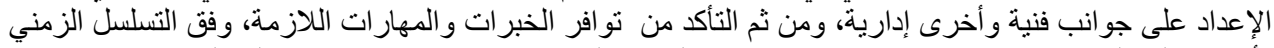

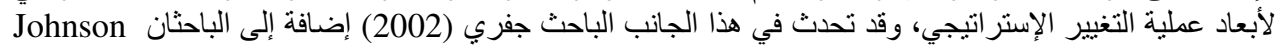

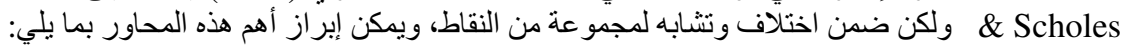

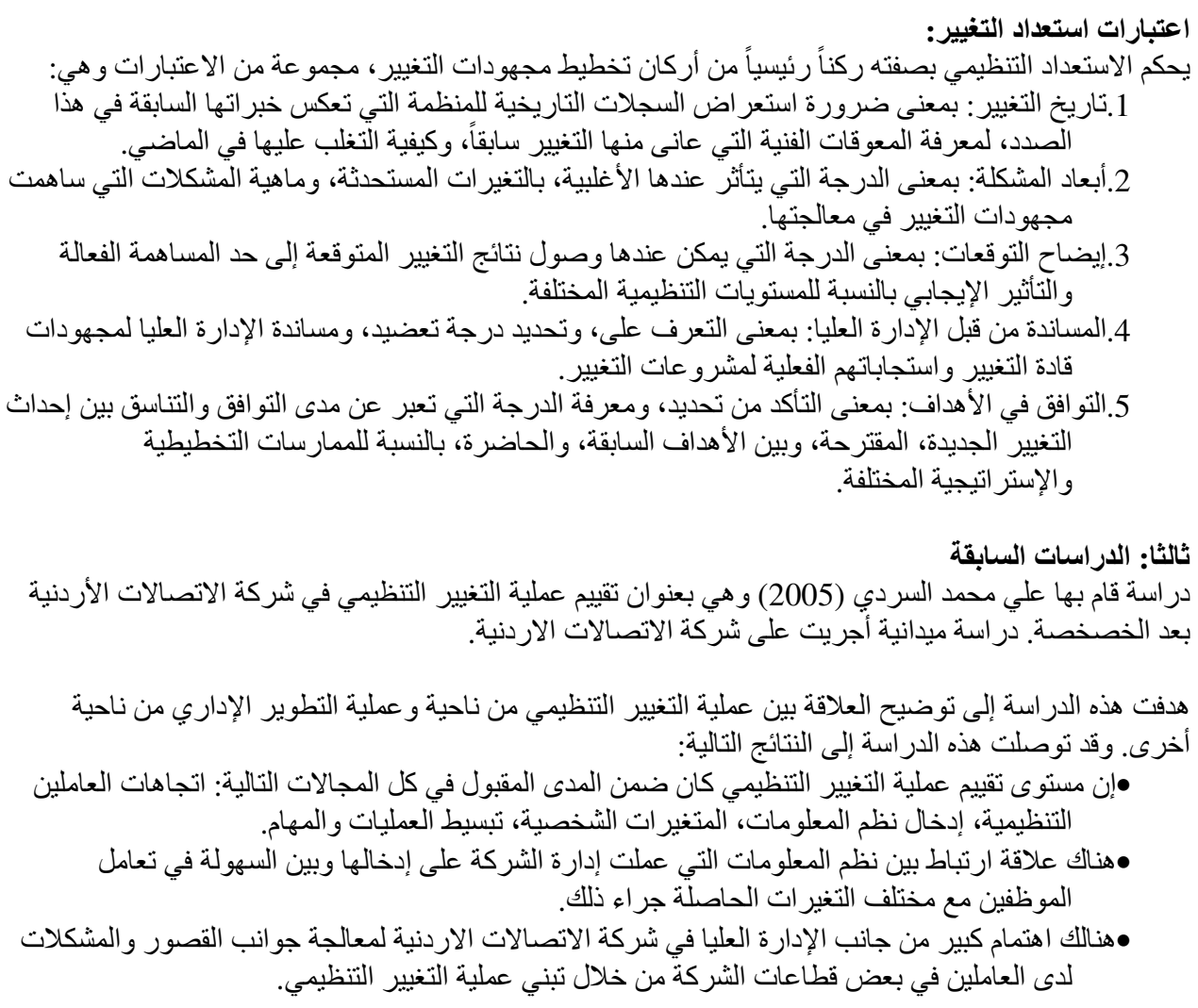


در اسة قام بها (مأمون احمد سليم الدقامسة 2002) وهي بعنوان التغيير التنظيمي : دراسة ميدانية لاتجاهات المديرين

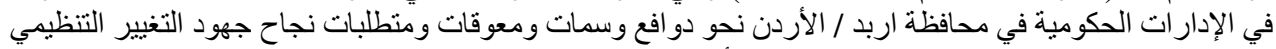

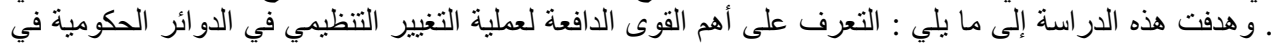

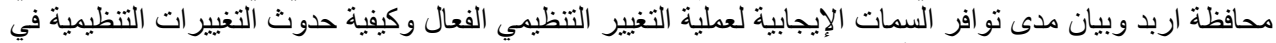

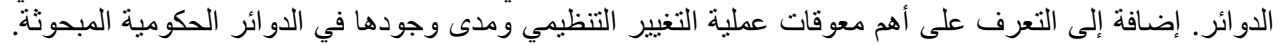

وقد خرجت هذه الدر اسة بالنتائج التالية:

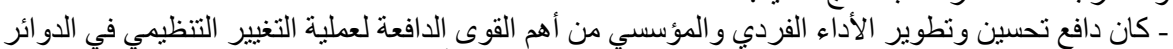

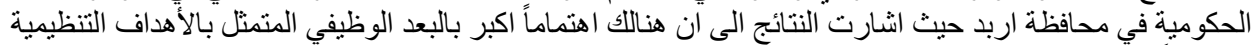

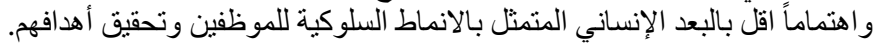

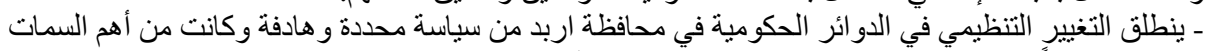

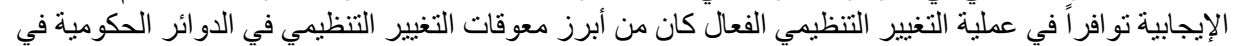

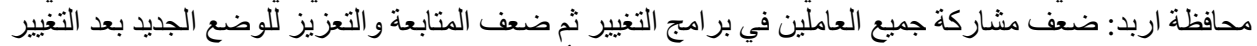

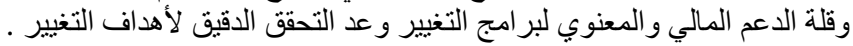

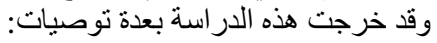

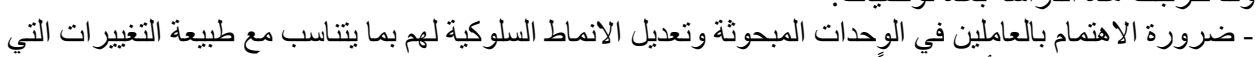

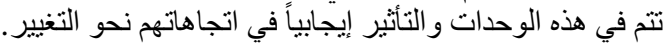

در اسة قام بها :(عبداله بن عبد الغني الطجم 2001 ) و هي بعنوان قياس درجة تأثير العاملين على أنواع القرارات

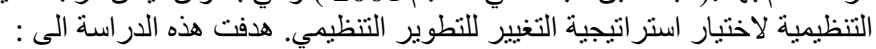

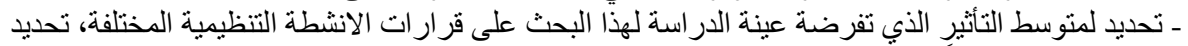

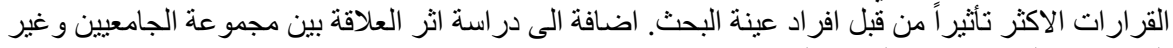

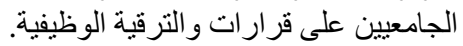

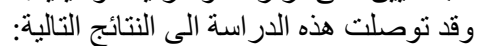

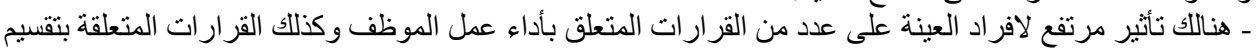

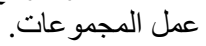

ـ هناللك تأثثير يتر اوح بين ضعيف او منعدم فيما يتعلق بقر ارات توزيع القوى العاملة كالتعيين و الترقية و الفصل من

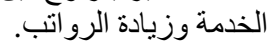

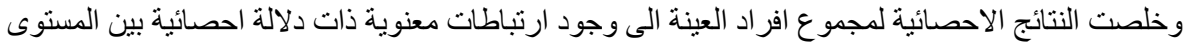

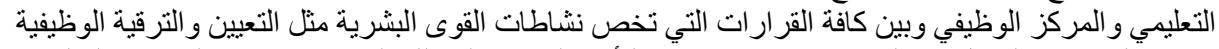

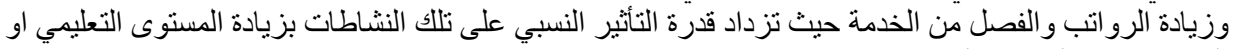

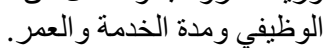

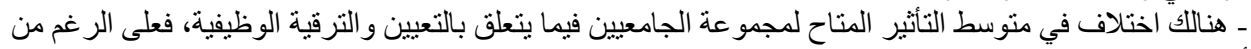

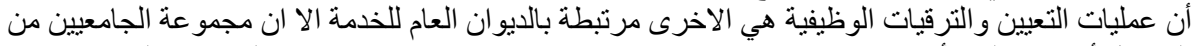

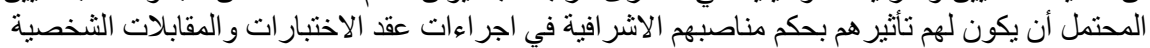

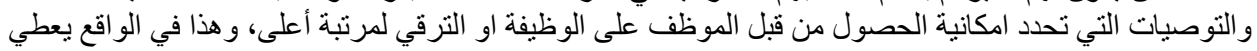
تللك الفئة من المستويات التعليمية قدرة في احداث التطوير التنظيمي المطلوب في ادارتهم او منظماتهم.

در اسة قام بها (سلطان نايف ابو تايه 2000) وهي بعنوان العو امل المؤثرة في التكيف مع التغيير في المسار الوظيفي: دراسة تطبيقية على موظفي شركة الاتصالات الاردنية.

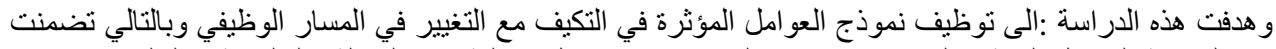

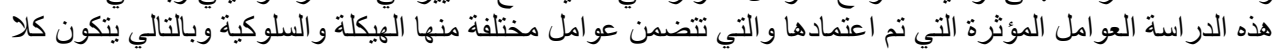

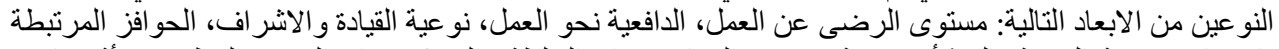

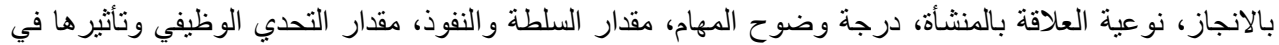

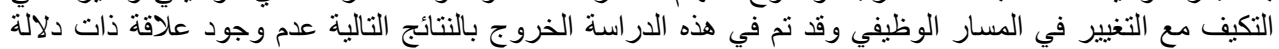

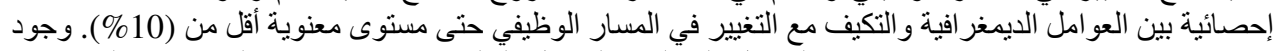
علاقة مهمة وذات دلالات إحصائية بين العوامل الهيكلية والعوالئية العل السلوكية مجتمعة وبين التكيف مع التغيير في المسار الوظيفي. 
Technological and Structural Inputs....

رابعا: نتائج الدراسة

ما هي مستويات التباين (الاختلاف) في نشاطات الدائرة بين الحالة الإدارية قبل وبعد تشغيل الثبكة الإلكترونية؟

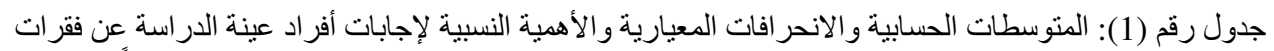

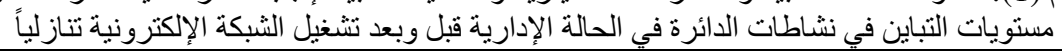

\begin{tabular}{|c|c|c|c|c|c|c|}
\hline اللمتوستبة & الأهمية & الاتحرا & المتوسد & الفقرة & رقة & الحتبب الحسبي \\
\hline متوسط & $\% 68$ & 1.042 & 3.40 & الدائرة في العلاقات الوظيفية داخل & 1 & 1 \\
\hline متوسط & $\% 66.2$ & 0.939 & 3.31 & الموظف في طوماً & 3 & 2 \\
\hline متوسط & $\% 65.2$ & 0.953 & 3.26 & الدائرة والدي العير الأخرى الوظيفية بين & 2 & 3 \\
\hline منوسط & $\% 64.8$ & 1.049 & 3.24 & المعاملات دي داخل الإدارة عمو احلٍ إنجاز & 4 & 4 \\
\hline منوسط & $\% 61.6$ & 1.069 & 3.08 & المعاملات في إجمالي الدائرة إنجاز & 6 & 5 \\
\hline متوسط & $\% 61$ & 1.113 & 3.05 & في الدائرة إجمالاً ويومياً المعادات المنجزة & 5 & 6 \\
\hline متوسط & $\% 64.4$ & 0.827 & 3.22 & الكل & & \\
\hline
\end{tabular}

يظهر من الجدول (1) أن المتوسطات الحسابية لفترات هذا البعد و المتعلقة بمسستويات التباين في نشاطات الدائرة بين

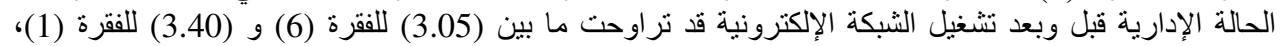

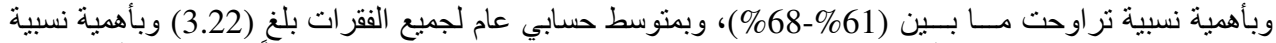

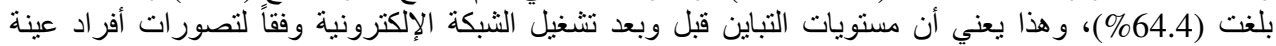
الدر اسة ذات مستوى متوسط.

ما هي مستويات الإرباك الإداري التي تحصل نتيجة تعطل الثبكة الإلكترونية في الشركة؟ 


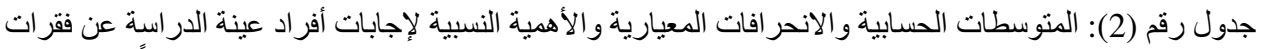
بعد مستويات الإربالك الإداري التي تحصل نتيجة تعطل الثبكة الإلكترونية في الثبكة الإنة تنازليا

\begin{tabular}{|c|c|c|c|c|c|c|}
\hline المبتوسبة & الأهمية & الانحرا & المستوسط & الفقرة & رقة & الترتيب \\
\hline متوسط & $\% 50.8$ & 1.202 & 3.54 & 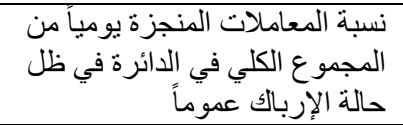 & 13 & 1 \\
\hline متوسط & $\% 50.6$ & 0.915 & 3.53 & 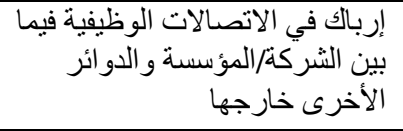 & 8 & 2 \\
\hline متوسط & $\% 50.2$ & 1.073 & 3.51 & إرباك في خطوات انجاز المعاملات & 10 & 3 \\
\hline منخفض & $\% 49.6$ & 1.011 & 2.48 & 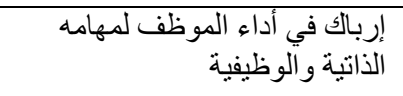 & 11 & 4 \\
\hline منخفض & $\% 49.4$ & 1.008 & 2.45 & و إلوبالك في توزيعات المهام والصات الوظيفية & 12 & 5 \\
\hline منخفض & $\% 46.8$ & 0.980 & 2.34 & 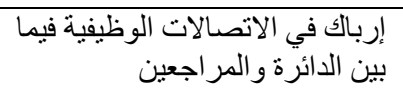 & 9 & 6 \\
\hline منخفض & $\% 46.4$ & 0.972 & 2.31 & 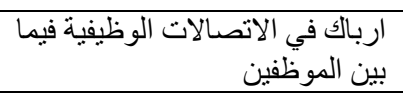 & 7 & 7 \\
\hline منخفض & $\% 49.6$ & 0.892 & 2.49 & & & \\
\hline
\end{tabular}

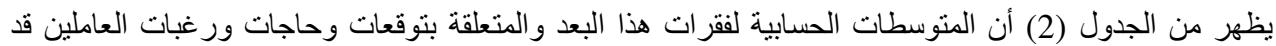

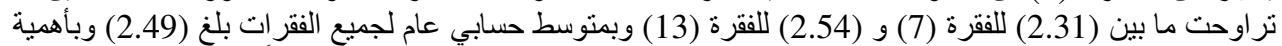

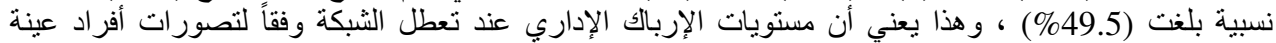

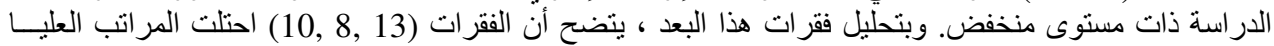

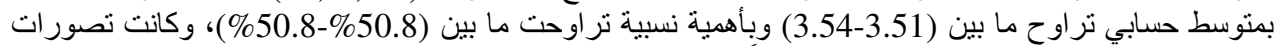

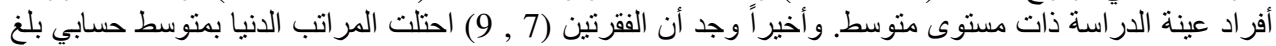

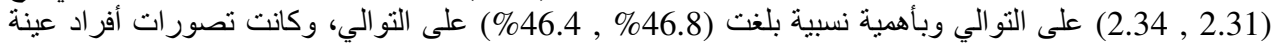
الدر اسة ذات مستوى منخفض.

ما هي الأبعاد الزمنية المعتادة لحالات الإرباك الإداري في حالات تعطل الثبكة الإلكترونية؟

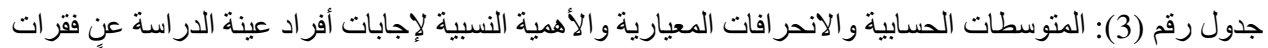

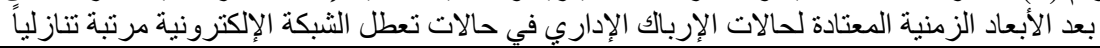

\begin{tabular}{|c|c|c|c|c|c|c|}
\hline اللمتوسبة المستوي & الألهبية & الانحرا & الحستبي & الفقرة & الفقرة & الرتيب حسب المسابي \\
\hline منخفض & $\begin{array}{c}\% 43 . \\
8\end{array}$ & 1.114 & 2.19 & معدل حالات توقن & 14 & 1 \\
\hline
\end{tabular}


Technological and Structural Inputs....

\begin{tabular}{|c|c|c|c|c|c|c|}
\hline منخفض & $\begin{array}{c}\% 40 . \\
6\end{array}$ & 0.991 & 2.03 & معدل الفترة الزماتية للتوقن & 15 & 2 \\
\hline منخفض & $\begin{array}{c}\% 42 . \\
7\end{array}$ & 0.969 & 2.11 & 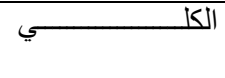 & & \\
\hline
\end{tabular}

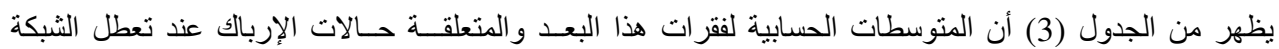

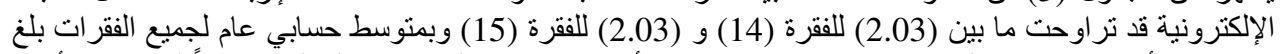

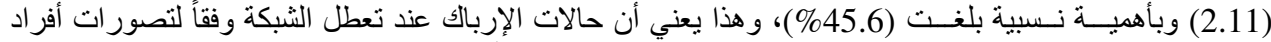

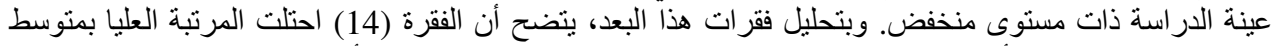

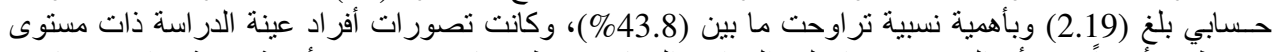

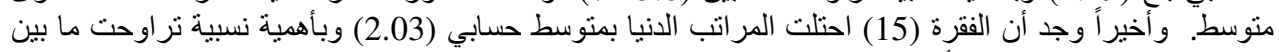
(40.6\%)، وكانت تصور ات أفر اد عينة الدر اسة ذات مستوى منخفض.

ما هي مستويات توظيف الطرق التالية تحاثياً لحالات توقف الثبكة الإلكترونية في الثركة؟ جدول رقم (4): المتوسطات الحسابية والانحر افات المعيارية والأهمية النسبية لإجابات أفر اد عينة الدراسة عن فقرات المستويات الوقائية لحالات توقف الثنبكة مرنبة تنازلياً

\begin{tabular}{|c|c|c|c|c|c|c|}
\hline اللمتسبة المستوى & الأهمية & الالمعراف & الحتوسطي & الفقرة & الفقرة & الرتبب المسب \\
\hline متوسط & $\% 65.4$ & 1.082 & 3.27 & زيادة كفاية أعداد الفنبين في مجال & 17 & 1 \\
\hline متوسط & $\% 65$ & 1.085 & 3.25 & الشيادة تجاوب لمتطلبات الموظفين من الجة توقة & 20 & 2 \\
\hline متوسط & $\% 64.4$ & 1.088 & 3.22 & تمعالجينة توقاية الدعم المالي الخاص & 19 & 3 \\
\hline متوسط & $\% 64.8$ & 1.130 & 3.19 & 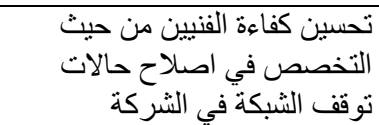 & 16 & 4 \\
\hline متوسط & $\% 58.8$ & 1.168 & 2.94 & زيادة استجابة ومبادرة الفنيين & 18 & 5 \\
\hline متوسط & $\% 58.8$ & 1.168 & 2.94 & 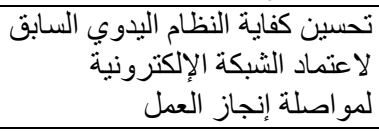 & 22 & 6 \\
\hline متوسط & $\% 58.6$ & 1.172 & 2.93 & 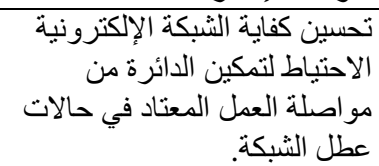 & 21 & 7 \\
\hline متوسط & $\% 62.2$ & 1.013 & 3.10 & الكلـــــي & & \\
\hline
\end{tabular}

يظهر من الجدول (4) أن المتوسطات الحسابية لفقرات هذا البعد والمتعلقة بالإجر اءات الوقائية قد تراوحت ما بئن

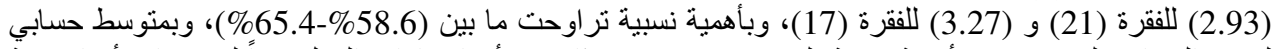

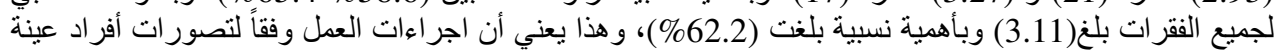
الدراسة ذات مستوى متوسط. 
ما هي مستويات توظيف الطرق التالية علاجيا عند حصول حالات توقف الثبكة الإلكترونية في الثركة عادة؟

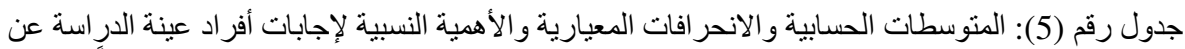

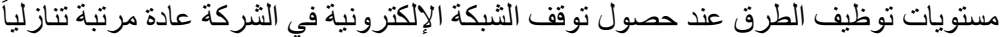

\begin{tabular}{|c|c|c|c|c|c|c|}
\hline المستوبة المستوى & الألهبية & المعياري & الحستوسطي & الفقرة & الفقرة & الحتبِ التربي \\
\hline مرتفع & $\% 71.2$ & 1.130 & 3.56 & المعاملة إلى اعتمة أثناء خطو عطل الثبكة الثباز & 26 & 1 \\
\hline مرتفع & $\% 71$ & 1.072 & 3.55 & 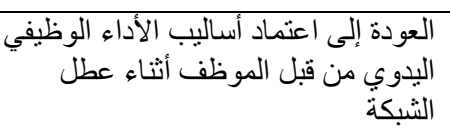 & 25 & 2 \\
\hline متوسط & $\% 67$ & 1.027 & 3.35 & 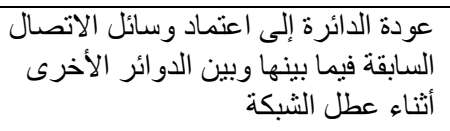 & 24 & 3 \\
\hline متوسط & $\% 65.6$ & 1.196 & 3.28 & 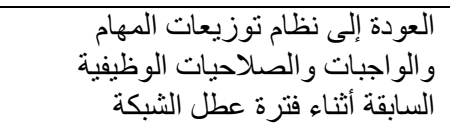 & 28 & 4 \\
\hline متوسط & $\% 65.2$ & 1.324 & 3.26 & 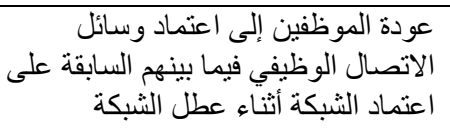 & 23 & 5 \\
\hline متوسط & $\% 64.6$ & 1.202 & 3.23 & 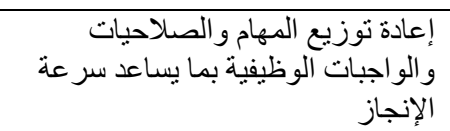 & 29 & 6 \\
\hline متوسط & $\% 63.2$ & 1.251 & 3.16 & اعتماد ساعات عمل إضافية & 31 & 7 \\
\hline متوسط & $\% 61.4$ & 1.140 & 3.07 & تالاديم محفز الوظيفي مناسبة لزيادة سر عة & 32 & 8 \\
\hline متوسط & $\% 54$ & 1.276 & 2.70 & العمل الجماعي المنهج الفرقي وتدعيم روح & 30 & 9 \\
\hline متوسط & $\% 64.8$ & 0.874 & 3.24 & الكل & & \\
\hline
\end{tabular}

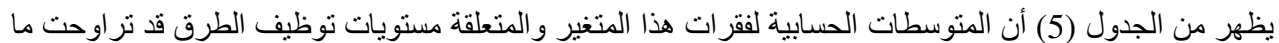

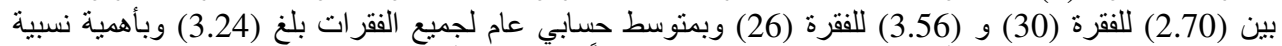

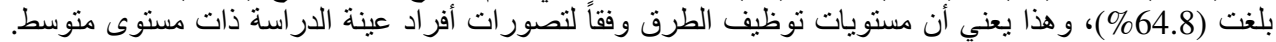

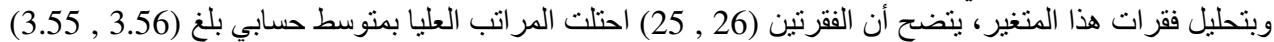

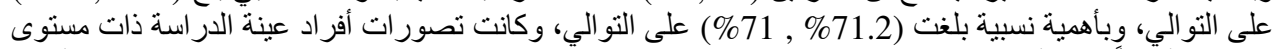

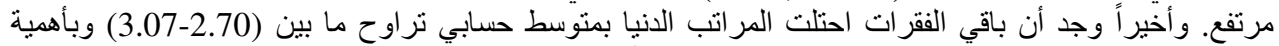

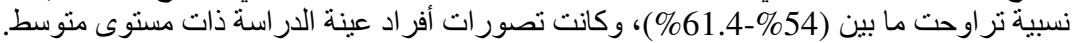




\section{Technological and Structural Inputs....}

خامسا: الاستنتاجات والتوصيات

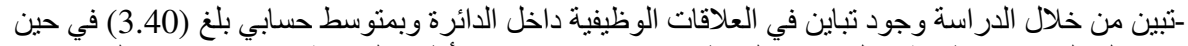

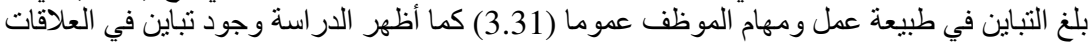

الوظيفية بين الدائرة و الدو ائر الأخرى بمتوسط حسابي المبن (3.26).

-تبين وجود حالة إربالك في إنجاز المعاملات المنجزة بومياً من المجموع الكئل الكتلي في الدائرة بمنتوسط حسابي

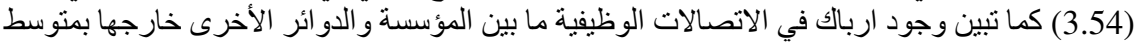

حسابي بلغ (3.53).

ـأما فيما يتعلق بمعدل حالات توقف الثبكة سنوياً، فقد تبين قلذة توقفها اذ بلغ متوسط حسابها (2.19) بالإضافة

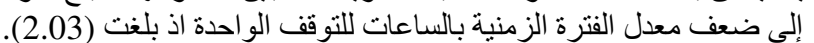

-كما توصلت الدر اسة إلى أن زيادة كفاية أعداد الفنيين في مجال اصلاح حالات توقف الفي الثبكة اذا بلغ المتوسط

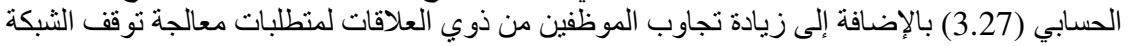

بمتوسط حسابي بلغ (3.25) بالاضنة

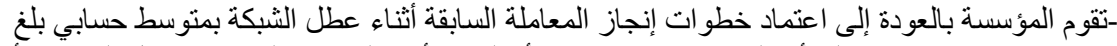

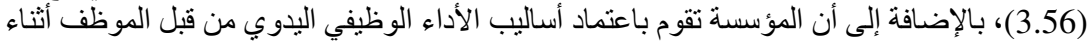

عطل الثبكة بوسط حسابي (3.55)، بالإنة المؤن

-كما أن الدو ائر في المؤسسة تعود إلى اعتماد وسائل الاتصال السابقة أثناء عطل الثبكة بوسط حسابي

\section{التوصيات

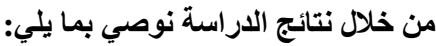

-نوصي الثركات التي تستخدم النظام الإلكتروني، بضرورة توفير بدائل عملية وسريعة عند وجود أي تعطل.

-نوصي الثركات المستخدمة للنظام الإكتروني، بضرورة توفير بدائل عملية وسريعة عند وجود أي تعطل. -ضرورة وجود فنيين على مدار الساعة، ليتمكنو ا من إصلاح أي عطل فني قد يحدث في الثركة.

ــلى المؤسسة أن تدعم الموظفين المختصين بإصلاح الأعطال في النظام الإلكتروني من خلال الدعم و الحو افز المادية بالإضافة إلى الدورات.

ـمتابعة كل ما هو جديد في مجال النظام الإلكتروني، كون المؤسسة ترنكز عليها بأسلوب عملها في المؤسسة.

المراجع باللغة العربية

-سلطان نايف ابو نايه، (2001)، "العو امل المؤثرة في التكيف مع التغيير في المسار الوظيفي: دراسة تطبيقية

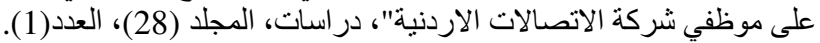

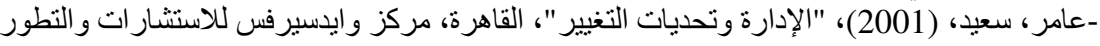

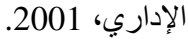

-عبداله بن عبد الغني الطجم، (2001)، "قياس درجة نأثير العاملين على أنو اع القرارات التنظيمية لاختبار

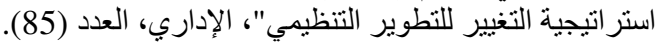

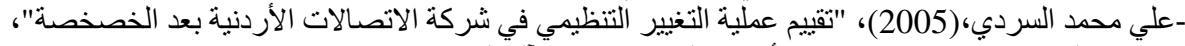

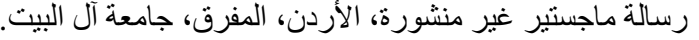

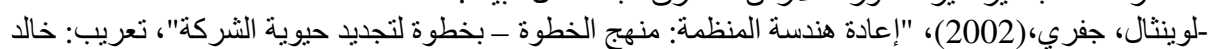
عبداله، مر اجعة: سرور سرور، إعادة دار المريخ للنشر، المملكة العربية السعودية، الرياض. 


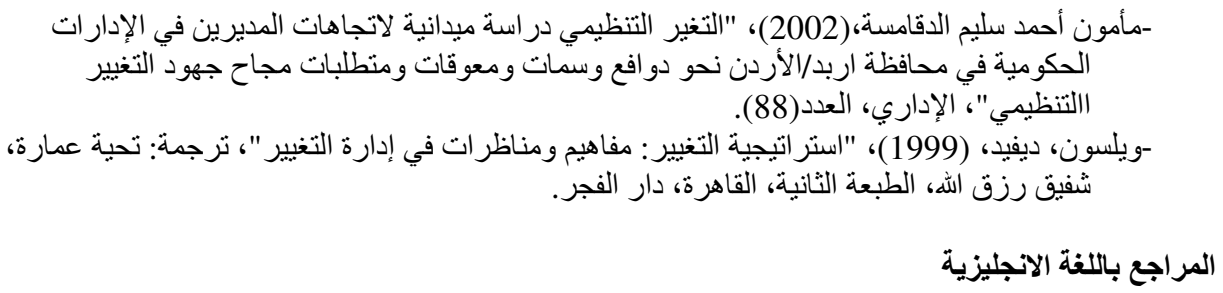

\section{References}

Alkalha, Z., Al-Zu'bi, Z., Al-Dmour, H., Alshurideh, M., and Masa'deh, R. (2012).

Investigating the Effects of Human Resource Policies on Organizational Performance: An

Empirical Study on Commercial Banks Operating in Jordan. European Journal of

Economics, Finance and Administrative Sciences 51, 44-64.

Hannagan, Tim, Management: Concept and Practices, Third Edition, Prentice Hall, USA.

Johnson, Jerry, and Scholes Kevan, (2002), Exploring Corporate Strategy, Text and Cases, Sixth Edition, Published under Financial Times-Prentice Hall, England.

Masa'deh, R., Obeidat, B., Zyod, D., and Gharaibeh, A. (2015). The Associations among Transformational Leadership, Transactional Leadership, Knowledge Sharing, Job Performance, and Firm Performance: A Theoretical Model. Journal of Social Sciences (COES\&RJ-JSS), 4 (2), 848-866.

Masa'deh, R., Obeidat, B., and Tarhini, A. (2015). A Jordanian Empirical Study of the Associations among Transformational Leadership, Transactional Leadership, Knowledge Sharing, Job Performance, and Firm Performance: A Structural Equation Modelling Approach. Journal of Management Development 35 (5), 681-705.

Schermerhorn, John, Management, Sixth Edition, New York, United States of America (USA).

Williams, Chuck, (2001), Effective Management - A Multimedia Approach, Prentice Hall, United States of America (USA). 